\title{
Reply to the comment to the paper (CNS-09-0420) "The clinical spectrum of Blake's pouch cyst: report of 6 illustrative cases" by Professor Charles Raybaud
}

\author{
Erwin M. J. Cornips • Christianne M. Hoeberigs • \\ Geke M. Overvliet • Alida A. Postma • \\ Johannes S. H. Vles
}

Received: 14 July 2010 / Accepted: 28 September 2010 / Published online: 7 October 2010

(C) The Author(s) 2010. This article is published with open access at Springerlink.com

\section{Dear Editor,}

We wish to thank Professor Raybaud for his valued comments [7] with regards to the embryology of the fourth ventricular outlet and the history of the terminology currently in use for cystic malformations of the posterior fossa $[2,4,10]$. In his original, well-illustrated paper published at the turn of the century, Blake states that "his investigations on the subject were prompted by the contradictory opinions and the lack of absolute knowledge concerning the nature of the communications between the cavity of the fourth ventricle and the subarachnoid space" [2]. Interestingly, to date, there are still "contradictory opinions and a lack of absolute knowledge" with regard to the spectrum of posterior fossa cysts and cyst-like malformations, including the one supposedly related to the embryological entity known as Blake's pouch, which is referred to as Blake's pouch cyst by some, and persisting Blake's pouch by others. Because of our incomplete

\author{
E. M. J. Cornips $(\square)$ \\ Department of Neurosurgery, \\ Maastricht University Medical Center, \\ PO box 5800, 6202 AZ Maastricht, The Netherlands \\ e-mail: erwincornips@yahoo.com \\ C. M. Hoeberigs $\cdot$ A. A. Postma \\ Department of Radiology, Maastricht University Medical Center, \\ PO box 5800, 6202 AZ Maastricht, The Netherlands \\ G. M. Overvliet \\ Department of Neurology, \\ Maastricht University Medical Center, \\ PO box 5800, 6202 AZ Maastricht, The Netherlands \\ J. S. H. Vles \\ Department of Child Neurology, \\ Maastricht University Medical Center, \\ PO box 5800, 6202 AZ Maastricht, The Netherlands
}

understanding of normal and abnormal embryological development in the posterior fossa, there are many descriptive terms, eponyms, classifications, and revised classifications $[1,5,6,9]$ that lack uniformity and add to the confusion.

A great deal of answers may be in anatomical and embryological studies that may nowadays include such sophisticated techniques as ultra high-field strength MR imaging, or phase-contrast cine MR imaging to evaluate cerebrospinal fluid flow [11]. However, in our opinion, everyday clinical practice requires a more practical approach, which was exactly the purpose of our paper [3]. Modern MR imaging techniques enable us to recognize distinct imaging features that may help identify subgroups in the spectrum of posterior fossa cysts and cyst-like malformations, as suggested by Barkovich et al. as early as 1989 [1]. Moreover and possibly of greater importance to clinicians, these techniques may enable us to identify children who may benefit from a specific surgical intervention (i.e., cyst fenestration, cyst shunting, ventricular shunting, endoscopic third ventriculostomy). In this regard, the most important questions might be (1) whether there is fourth ventricular outflow obstruction and resulting hydrocephalus and (2) whether there are associated (developmental) anomalies.

We were inspired by the paper of Tortori-Donati et al. [9] who proposed a practical classification for those cystic malformations of the posterior cranial fossa originating from a defect of the posterior membranous area. According to these authors, in the absence of anomalies of the anterior membranous area (i.e., when vermis, cerebellar hemispheres, and fourth ventricle are roughly normal) a defect of the posterior membranous area may produce two distinct malformations: mega cisterna magna and persisting Blake's pouch. Still according to these authors, a mega cisterna 
magna should be clinically silent (no symptoms or signs secondary to compression of the nervous and ventricular structures of the posterior fossa), should not produce hydrocephalus, and should never be treated. Differential diagnosis in case of a dilated retrocerebellar subarachnoid space and an associated hydrocephalus should be either an arachnoid cyst (produced by an entirely different mechanism that does not involve the posterior membranous area), an acquired encystment of the fourth ventricle (e.g., posthemorrhagic, postinfectious, or postoperative), or a Blake's pouch cyst. The latter is defined as a failure of regression of Blake's pouch (hence the term "persisting Blake's pouch") secondary to non-perforation of the foramen of Magendi, resulting in a posterior ballooning of the superior medullary velum into the cisterna magna. As such, according to these authors, a persisting Blake's pouch should communicate freely with the fourth ventricle, and should always be accompanied by hydrocephalus. Moreover, it may (or may not) produce symptoms early or late in life [3] pretty much in the same way as in congenital aqueductal stenosis. Tortori-Donati et al. [9] continue that shunting of either the lateral ventricles or the pouch restores the ventricular system to a normal size and allows reexpansion of the compressed cerebellum, while the pouch diminishes in size or completely collapses.

Such practical radiological classifications are appealing and easy to apply in everyday clinical practice. As such, we reported six cases with a retrocerebellar cyst that appeared to communicate freely with the fourth ventricle, an associated hydrocephalus, and a roughly normal vermis, cerebellar hemispheres, and fourth ventricle configuration [3]. We admit we had some discussions about the first child who died and had an autopsy, but decided to include the case for several reasons. First, it did look like an acute bleeding into a preexistent posterior fossa cyst-like malformation that may have acted as a locus minoris resistentiae when (for unrelated reasons) the child developed a coagulation disorder. Second, to attract the readers' attention underscoring the wide clinical spectrum of Blake's pouch cyst, that may on the other end of the spectrum remain asymptomatic throughout life. Moreover, whereas Tortori-Donati et al.[9] suggested a treatment involving some kind of shunting, we successfully treated three symptomatic cases by means of an endoscopic third ventriculostomy, and suggest this may be regarded the best current treatment option for symptomatic Blake's pouch cyst.

Also of interest, some years earlier than Tortori-Donati, Strand et al. [8] proposed a unified embryological theory with regard to posterior fossa cysts and cyst-like malformations. These authors emphasize that it is more important to describe the morphologic findings (using a kind of checklist proposed in their material and methods section) than to label the retrocerebellar cyst with an eponym. They point out that it is of particular importance whether the retrocerebellar cyst is associated with a malformed hindbrain (i.e., true cerebellar hypoplasia), a deformed hindbrain (i.e., merely mass effect on a roughly normal cerebellum), or both, as the two may actually coexist, illustrating every classification in the end is somewhat arbitrary. Moreover, of equal importance is the detection and delineation of other central nervous system anomalies, as well as aqueductal patency in case of an associated hydrocephalus [8].

Finally, we fully agree with Professor Raybaud's comment [7] that an extraventricular hydrocephalus caused by arachnoid encystment after an intraventricular hemorrhage should be included in the differential diagnosis. However, because imaging as well as therapeutic options are pretty much the same for both entities, again from a practical standpoint, distinguishing both entities despite their different etiology (one congenital, the other one acquired) may not be necessary.

In conclusion, over the years, the eponyms Blake's pouch cyst and persisting Blake's pouch have been used inconsequently in the literature on posterior fossa cysts and cyst-like malformations. From a practical standpoint, however, as well as for the sake of clarity, we would agree with Tortori-Donati et al. [9] that Blake's pouch cyst should be regarded as a separate entity, involving a retrocerebellar cyst that appears to communicate freely with the fourth ventricle, an associated hydrocephalus that may or may not become symptomatic, and a roughly normal vermis, cerebellar hemispheres, and fourth ventricle configuration. Importantly, not all posterior fossa cysts and cyst-like malformations with an associated hydrocephalus are a Dandy-Walker or a Dandy-Walker variant (defect of the anterior membranous area). They may be a Blake's pouch cyst (defect of the posterior membranous area), or may even be acquired (secondary arachnoidal adhesions causing fourth ventricular outflow obstruction). We suggest that endoscopic third ventriculostomy may be regarded the best current treatment option for symptomatic Blake's pouch cyst.

Open Access This article is distributed under the terms of the Creative Commons Attribution Noncommercial License which permits any noncommercial use, distribution, and reproduction in any medium, provided the original author(s) and source are credited.

\section{References}

1. Barkovich AJ, Kjos BO, Noman D, Edwards MS (1989) Revised classification of posterior fossa cysts and cystlike malformations based on the results of multiplanar MR imaging. Am J Roentgenol 153:1289-1300

2. Blake JA (1900) The roof and lateral recesses of the fourth ventricle, considered morphologically and embryologically. J Comp Neurol 10:79-108 
3. Cornips EMJ, Overvliet GM, Weber JW, Postma AA, Hoeberigs CM, Baldewijns MMLL et al (2010) The clinical spectrum of Blake's pouch cyst: report of six illustrative cases. Child's Nervous System. doi:10.1007/s00381-010-1085-2

4. Dandy WE (1921) The diagnosis and treatment of hydrocephalus due to occlusion of the foramina of Magendi and Luschka. Surg Gynecol Obstet 32:112

5. Kolias SS, Ball WS Jr, Prenger EC (1993) Cystic malformation of the posterior fossa: differential diagnosis clarified through embryologic analysis. Radiographics 13:1211-1231

6. Nelson MD Jr, Mahler K, Gilles FH (2004) A different approach to cysts of the posterior fossa. Pediatr Radiol 34:720-732

7. Raybaud R (2010) Comment to the paper (CNS-09-0420) "The clinical spectrum of Blake's pouch cyst: report of six illustrative cases". Child's Nerv Syst. doi:10.1007/s00381-010-1116-z
8. Strand RD, Barnes PD, Young Poussaint T, Estroff JA, Burrows PE (1993) Cystic retrocerebellar malformations: unification of the Dandy-Walker complex and the Blake's pouch cyst. Pediatr Radiol 23:258-260

9. Tortori-Donati P, Fondelli MP, Rossi A, Carini S (1996) Cystic malformation of the posterior cranial fossa originating from a defect of the posterior membranous area, mega cisterna magna and persisting Blake's pouch: two separate entities. Child's Nerv Syst 12:303-308

10. Walker AE (1944) A case of congenital atresia of the foramina of Luschka and Magendi. J Neuropathol Exp Neurol 3:368-373

11. Yildiz H, Yazici Z, Hakyemez B, Erdogan C, Parlak M (2006) Evaluation of CSF flow patterns of posterior fossa cystic malformations using CSF flow MR imaging. Neuroradiology 48:595-605 